\title{
A Comparison of Genospecies of Clinical Isolates in the Acinetobacter spp. Complex Obtained from Hospitalized Patients in Busan, Korea
}

\author{
Gyu-Nam Park ${ }^{1, *}$, Hye-Sook Kang ${ }^{2, * *}$, Hye-Ran Kim ${ }^{3, * * *}$, Bo-Kyung Jung ${ }^{1, *}$, \\ Do-Hee Kim ${ }^{4, *}$ and Kyung-Soo Chang ${ }^{1, \dagger, * * *}$ \\ ${ }^{I}$ Department of Clinical Laboratory Science, College of Health Sciences, \\ Catholic University of Pusan, Busan 46252, Korea \\ ${ }^{2}$ Department of Laboratory Medicine, Maryknoll Medical Center, Busan 48972, Korea \\ ${ }^{3}$ Department of Clinical Laboratory Science, College of Health and Therapy, \\ Daegu Haany University, Gyeongsangbuk-Do 38610, Korea \\ ${ }^{4}$ Department of Laboratory Medicine, Busan Veterans Hospital, Busan 46996, Korea
}

\begin{abstract}
Of the Acinetobacter spp., A. baumannii (genospecies 2) is the most clinically significant in terms of hospital-acquired infections worldwide. It is difficult to perform Acinetobacter-related taxonomy using phenotypic characteristics and routine laboratory methods owing to clusters of closely related species. The ability to accurately identify Acinetobacter spp. is clinically important because antimicrobial susceptibility and clinical relevance differs significantly among the different genospecies. Based on the medical importance of pathogenic Acinetobacter spp., the distribution and characterization of Acinetobacter spp. isolates from 123 clinical samples was determined in the current study using four typically applied bacterial identification methods; partial rpoB gene sequencing, amplified rRNA gene restriction analysis (ARDRA) of the intergenic transcribed spacer (ITS) region of the 16 23S rRNA, the VITEK $^{\circledR} 2$ system (an automated microbial identification system) and matrix-assisted laser desorption/ionization-time of flight mass spectrometry (MALDI-TOF MS). A. baumannii isolates $(74.8 \%, 92 / 123)$ were the most common species, A. nosocomialis $(10.6 \%, 13 / 123)$ and A. pittii isolates $(7.5 \%, 9 / 123)$ were second and third most common strains of the A. calcoaceticus-A. baumannii (ACB) complex, respectively. A. soli $(5.0 \%, 6 / 123)$ was the most common species of the non-ACB complex. RpoB gene sequencing and ARDRA of the ITS region were demonstrated to lead to more accurate species identification than the other methods of analysis used in this study. These results suggest that the use of rpoB genotyping and ARDRA of the ITS region is useful for the species-level identification of Acinetobacter isolates.
\end{abstract}

Key Words: Acinetobacter spp., Genomic species, RpoB genotyping, ARDRA of the ITS region, MALDI-TOF MS, Colony morphology

\section{INTRODUCTION}

The genus Acinetobacter belongs to the order Pseudomona- dales and family Moraxellaceae. It comprises Gram-negative, non-motile, oxidase-negative, glucose non-fermenting, strictly aerobic and catalase-positive coccobacilli rods. To date, more than 40 Acinetobacter species have been described. Of these,

Received: December 18, 2018 / Revised: January 10, 2019 / Accepted: January 14, 2019

* Graduate student, ${ }^{* *}$ Researcher, ${ }^{* * *}$ Professor.

†Corresponding author: Kyung-Soo Chang. Department of Clinical Laboratory Science, College of Health Sciences, Catholic University of Pusan, Busan 46252, Korea.

Tel: +82-51-510-0565, Fax: +82-51-510-0568, e-mail: kschang@cup.ac.kr

(C) The Korean Society for Biomedical Laboratory Sciences. All rights reserved.

(c) This is an Open Access article distributed under the terms of the Creative Commons Attribution Non-Commercial License (http://creativecommons.org/licenses/by-nc/3.0/) which permits unrestricted non-commercial use, distribution, and reproduction in any medium, provided the original work is properly cited. 
A. baumannii is the most clinically significant because it is closely associated with nosocomial infections. It is also most frequently found in clinical samples. A. baumannii is associated with a wide range of infections, including bacteraemia, meningitis, pneumonia, urinary tract infection, ventilator associated pneumonia, and wound infections. In recent years, infection due to other Acinetobacter spp. that belong to the A. calcoaceticus-A. baumannii (ACB) complex (including $A$. calcoaceticus, $A$. nosocomialis and $A$. pittii) has raised major concerns worldwide (Vaneechoutte et al., 1995; Cisneros et al., 2002; Lee et al., 2011; Visca et al., 2011; Tien et al., 2012; Almasaudi, 2018).

The rapid and accurate identification of pathogens, and in particular, Acinetobacter spp., is a clinically important objective in clinical microbiology. This is primarily because different genospecies have differing biological characteristics and pathogenicity, and this can be relevant when seeking to ensure treatment efficacy. However, identification at the individual species level of Acinetobacter is difficult because Acinetobacter spp. are very similar phenotypically, while being closely related genetically. As a result, the traditional approaches used to for identify non-baumannii Acinetobacter species often result in the latter being falsely identified as $A$. baumannii. Therefore, the development of reliable identification methods has been the focus of recent studies. Several genotypic methods have been found to be effective when seeking to differentiate the Acinetobacter spp. isolates from one another. Of the molecular techniques employed, sequence analysis of the 16 23S rRNA or $r p o B$ genes is widely used in clinical microbiology laboratories. However, these approaches are not sufficiently polymorphic to successfully differentiate between the different Acinetobacter species. A number of genomic fingerprinting methods have been proposed for genospecies typing. Amplified rRNA gene restriction analysis (ARDRA) and amplified fragment length polymorphism (AFLP) analysis are examples of useful genomic fingerprinting techniques that are used for clinical identification. However, these methods are laborious, especially when a large group of isolates is under consideration (Koeleman et al., 1998; Cisneros et al., 2002; Lee et al., 2014; Wang et al., 2014).

Matrix-assisted laser desorption/ionization time-of-flight mass spectrometry (MALDI-TOF MS), a rapid, accurate, and low-cost technique, is successfully utilized to achieve microbial characterization and identification. This technology is applied to identify diverse microorganisms, including bacteria, fungi and viruses in clinical microbiology laboratories (Croxatto et al., 2012; Dingle and Butler-Wu, 2013; Jeong et al., 2016).

The study objective was to compare the identification accuracy of four typically applied bacterial identification methods; partial $r p o B$ gene sequencing, ARDRA of the ITS region of the 16 23S rRNA gene, the VITEK $^{\circledR} 2$ system (an automated microbial identification system), and MALDITOF MS. Although the epidemiology of pathogenic Acinetobacter spp. has been described, there are few data on pathogenic Acinetobacter spp. in Korea. Motivated by on the medical importance of pathogenic Acinetobacter spp., an evaluation was performed in the current study of the isolation frequency and characterization of Acinetobacter spp. clinical isolates from various clinical samples collected from general hospitals in Busan, Korea, between 2013 and 2015.

\section{MATERIALS AND METHODS}

\section{Bacterial isolates}

One hundred and twenty-three non-duplicate clinical isolates of Acinetobacter strains, which were collected from two general hospitals in Busan, Korea (between March 2013 and February 2015); 68 isolates from sputum (55.3\%), 17 isolates from blood (13.8\%), 14 isolates from urine (11.4\%), 7 isolates bronchial fluid (5.7\%), 6 isolates from wound (4.9\%), 5 isolates from foley catheter $(4.1 \%)$, and 3 isolates from pus and ear, respectively (2.4\%). All the isolates were identified as Acinetobacter spp. using an automated microbial identification system $\left(\right.$ VITEK $^{\circledR} 2$; bioMerieux, Marcy l'Etoile, France) utilized in conjunction with the VITEK $^{\circledR} 2$ GN-ID card. Reference strain American Type Culture Collection [ATCC] 19606 (A. baumannii, genospecies 2) was purchased. The clinical isolates and reference strain were stored at $-70^{\circ} \mathrm{C}$ in a freezer prior to use.

\section{Cultures and isolation}

The clinical isolates were recovered by using blood agar 
Table 1. Primer pair used in the experiment for $r p o B$ gene amplification

\begin{tabular}{clcc}
\hline \hline Gene & \multicolumn{1}{c}{ Sequence (5' to 3') } & Product size (bp) & Reference \\
\hline \multirow{2}{*}{$r p o B$} & Forward: TAC CGT AAA GAC TTG AAA GAA G & 380 & La Scola et al., 2006 \\
& Reverse : CAA CAC CTT TGT TCC CGT GA & & \\
\hline
\end{tabular}

that containing 5\% sheep blood. The agar plates were incubated in the dark at $37^{\circ} \mathrm{C}$ under a humid conditions for 24 48 hrs. The plates were examined daily to search for the appearance of pure colonies. The colonies were sub-cultured on MacConkey agar for the pure isolation of Acinetobacter isolates.

\section{Bacterial genomic DNA extraction of the isolates}

The clinical isolates were incubated in a brain-heart infusion (BHI) broth at $37^{\circ} \mathrm{C}$ for $18 \mathrm{hrs}$ for genotyping. The genomic DNA of each of the 123 Acinetobacter clinical isolates was extracted using the Accuprep ${ }^{\circledR}$ Genomic DNA extraction kit (Bioneer, Daejeon, Korea). Bacterial genomic DNA extraction was performed according to the manufacturer's instructions. The extracted genomic DNA was stored at $-20{ }^{\circ} \mathrm{C}$ prior to further molecular analysis.

\section{The rpoB gene amplification and sequencing}

The $r p o B$ gene amplification and sequencing was performed using a specific oligonucleotide primer set for genospecies identification of the clinical isolates (Table 1). PCR was performed using the following optimum conditions: initial denaturation at $94^{\circ} \mathrm{C}$ for $5 \mathrm{~min}$, followed by 35 cycles of $94^{\circ} \mathrm{C}$ for $1 \mathrm{~min}$ (denaturation), $55^{\circ} \mathrm{C}$ for $30 \mathrm{sec}$ (annealing), and $72{ }^{\circ} \mathrm{C}$ for $90 \mathrm{sec}$ (extension), and a final extension at $72^{\circ} \mathrm{C}$ for $7 \mathrm{~min}$. The expected amplification size (of the PCR product) was approximately $380 \mathrm{bp}$. The PCR products were analyzed by electrophoresis (100 V for $25 \mathrm{~min}$ ) with $1.5 \%$ agarose gel that contained ethidium bromide $(\mathrm{EtBr})$ and visualized under ultraviolet (UV) light. The amplified genomic DNA of the isolates in the gel was purified using the Accuprep ${ }^{\circledR}$ Gel Purification Kit (Bioneer, Daejeon, Korea). The purified PCR products were sequenced via the sequencing service provided by a professional molecular analysis facility (CosmoGENTECH Inc., Seoul, Korea). After sequencing the DNA, the sequences were compared to available reference data in the Genbank database using Basic Local Alignment Search Tool (BLAST) to determine species identification.

\section{Amplified rRNA gene restriction analysis of the ITS region}

ARDRA of the ITS region of the 16 23S rRNA was performed to identify genospecies of the isolates. The sequences of the primers were 5'-TGG CTC AGA TTG AAC GCT GGC GGC-3' (forward) and 5'-TAC CTT GTT ACG ACT TCA CCC CA-3' (reverse).

PCR was performed using the following optimum conditions: initial denaturation at $94^{\circ} \mathrm{C}$ for $5 \mathrm{~min}$, followed by 35 cycles of $94^{\circ} \mathrm{C}$ for $1 \mathrm{~min}$ (denaturation), $55^{\circ} \mathrm{C}$ for $1 \mathrm{~min}$ (annealing), and $72{ }^{\circ} \mathrm{C}$ for $90 \mathrm{sec}$ (extension), and a final extension at $72^{\circ} \mathrm{C}$ for $7 \mathrm{~min}$. The length of the amplified product was approximately $1,300 \mathrm{bp}$. Five restriction enzymes, AluI (AGCT), HhaI (GCGC), HaeIII (GGCC), MboI (GATC), and MSPI (CCGG) (Enzynomics, Daejeon, Korea), were used for DNA digestion, performed according to the manufacturer's instructions. The restriction fragment pattern of each sample was separated by $2 \%$ agarose gel electrophoresis $(100 \mathrm{~V}$ for $1 \mathrm{hr})$ in $1 \times$ Tris-bortate EDTA buffer and visualized under UV illumination.

\section{Phylogenetic and genetic characterization analysis}

The $r p o B$ gene sequences obtained from positive Acinetobacter spp. samples were analyzed to determine the genospecies. Multiple sequence alignment and sequence comparisons, including reference sequences that corresponding with genospecies in the GenBank database, were made using the Clustal W (ver. 2.1) software.

Phylogenetic analysis was performed using the MaximumLikelihood (ML) method in MEGA 6.0 software. Nucleotide distances ( $p$-distance) and 1,000 replications were employed in the bootstrap analysis. 

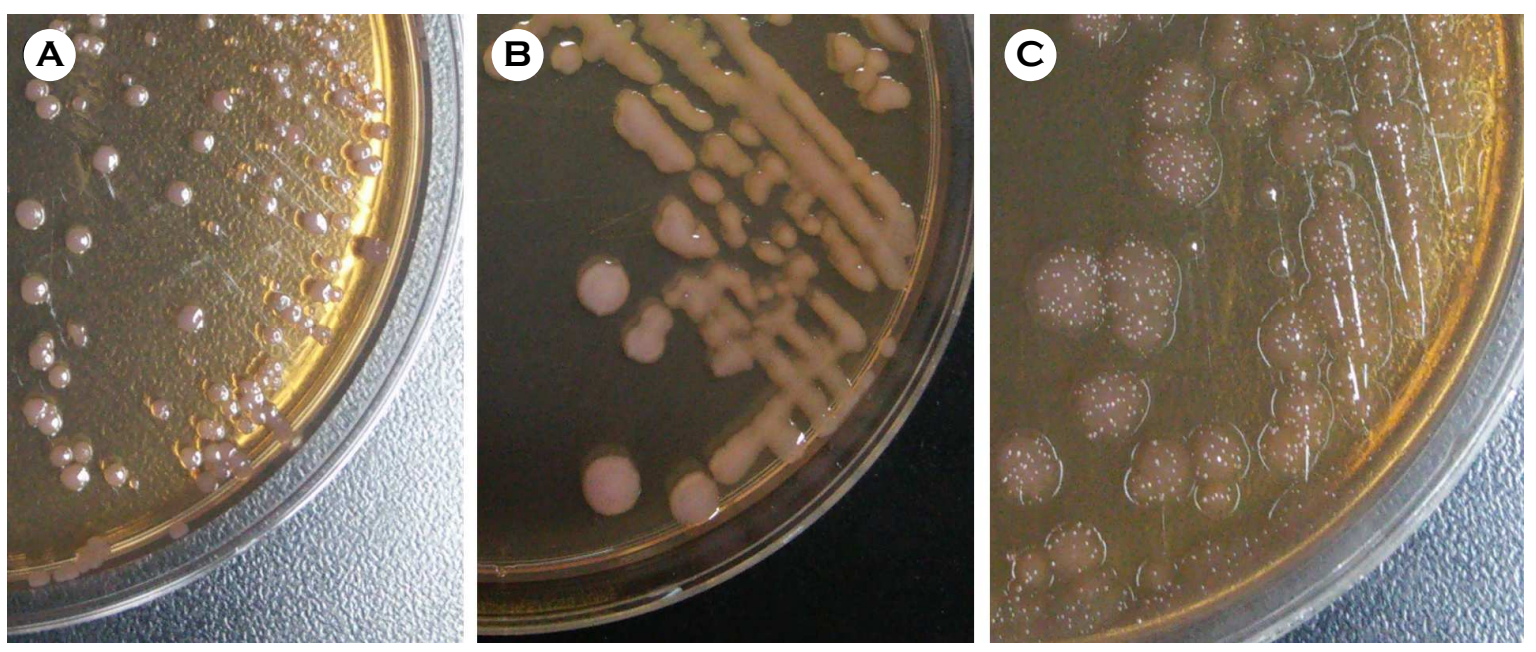

Fig. 1. Characterization of colonies of Acinetobacter spp. clinical isolates on MacConkey agar plates after incubation 24 hrs. (A) Group A isolates appeared as colorless small size smooth colonies with circular margin. (B) Group B isolates appeared as colorless medium size mucoid colonies. (C) Group C isolates appeared as colorless medium size rough colonies.

\section{MALDI-TOF MS analysis}

Measurements were performed on VITEK $^{\circledR}$ MS instrument equipped with both IVD 2.0 and RUO databases (bioMerieux, Marcy l'Etoile, France). The isolates were identified on the VITEK $^{\circledR}$ MS system in accordance with the manufacturer's instructions. Escherichia coli (E. coli) ATCC 8739 was used as the calibration strain.

\section{RESULTS}

\section{The diversity of Acinetobacter spp. colony morphology} on MacConkey agar plates

Colony morphology examination is an important method of bacteria identification. MacConkey agar is commonly used for the detection of Acinetobacter spp. in clinical cultures. In the current study, the isolates were classified as three different morphotypes according to colony color (pigmentation) and shape (including form, elevation, and margin) on MacConkey agar plates (Fig. 1). One-hundred one isolates (Group A, 82.1\%) were observed to be small in size ( $<3 \mathrm{~mm}$ ), smooth (the entire margin), round (circular form), and raised colonies on the MacConkey agar plates following incubation for 24 hrs. Sixteen isolates (Group B, 13.0\%) were seen to be of a medium size (3 5 mm), smooth (the entire margin), shiny, round (circular form), and characterized by slightly mucoid colonies. Six isolates (Group C, 4.9\%) were of a medium size, rough, irregular and characterized by flat colonies.

None of the Acinetobacter spp. isolates produced any pigment. Non-lactose fermenting colonies (colorless or light lavender color) were observed. The colonies of all isolates were Gram-negative (data not shown).

\section{Phenotypic identification of Acinetobacter spp. isolates using the VITEK ${ }^{\circledR} 2$ system}

VITEK $^{\circledR} 2$, an automated microbial identification system, is frequently used to rapidly identify pathogens in clinical laboratories around the world. The clinical isolates in the current study were identified using the VITEK ${ }^{\circledR} 2$ system in conjunction with the GN-ID card. All the isolates $(n=123$, $100.0 \%$ ) were identified as A. baumannii (genospecies 2) (Table 2).

\section{Genotypic identification of Acinetobacter spp. isolates using the rpoB gene sequencing}

Fig. 2 shows the PCR amplification results for the $r p o B$ gene. One-hundred and twenty three Acinetobacter clinical isolates were analyzed using the $r p o B$ gene genotyping (Supplementary data 1). Five Acinetobacter spp. were identi- 


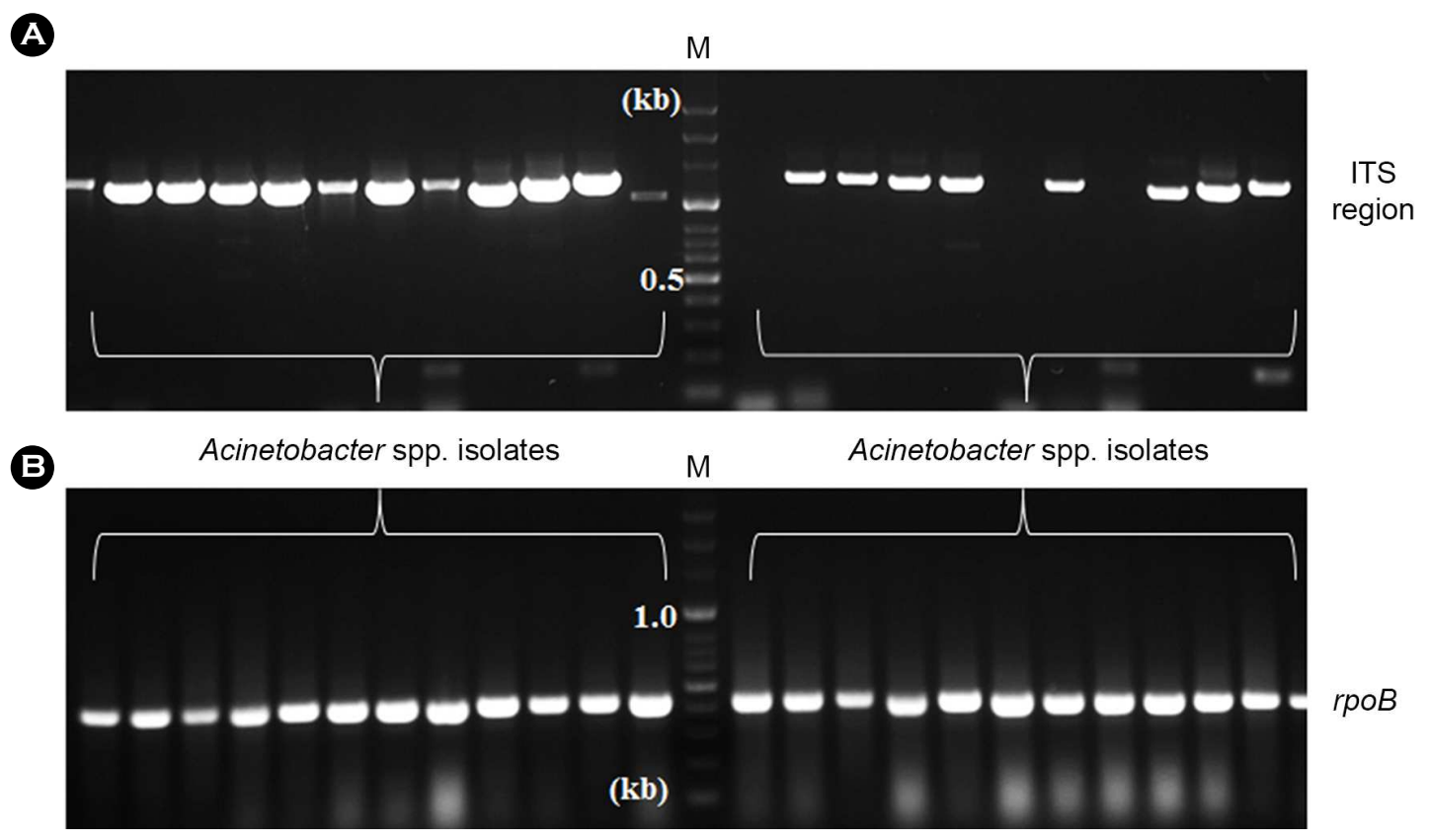

Fig. 2. ITS region and $r p o B$ gene amplification of Acinetobacter spp. isolates by PCR. Lanes M; 100 bp molecular marker (Bioneer, Seoul), the others; PCR products of Acinetobacter spp. isolates. (A) ITS region was amplified specific fragments of 1,300 bp in Acinetobacter spp. isolates. (B) $r p o B$ gene was amplified specific fragments of $400 \mathrm{bp}$ in Acinetobacter spp. isolates.

Table 2. Detailed results of the identification of 123 Acinetobacter clinical isolates obtained using the $r p o B$ gene sequencing, ITS region sequencing, the MALDI-TOF MS based VITEK ${ }^{\circledR}$ MS, and the VITEK $^{\circledR} 2$

\begin{tabular}{|c|c|c|c|c|c|c|c|}
\hline \multirow{3}{*}{ Groups } & \multirow{3}{*}{$\begin{array}{c}\text { Final } \\
\text { Identification } \\
\text { (No. of isolates) }\end{array}$} & \multirow{3}{*}{$\begin{array}{l}\text { Colony } \\
\text { type (n) }\end{array}$} & \multicolumn{5}{|c|}{ Identification results } \\
\hline & & & \multicolumn{2}{|c|}{ Gene sequencing } & \multicolumn{2}{|c|}{ MALDI-TOF MS (VITEK ${ }^{\circledR}$ MS) } & \multirow{2}{*}{$\begin{array}{l}\text { VITEK }^{\circledR} 2 \\
\text { system (n) }\end{array}$} \\
\hline & & & $r p o B(\mathrm{n})$ & ITS (n) & IVD $2.0(\mathrm{n})$ & RUO v 4.13 (n) & \\
\hline \multirow{4}{*}{$\begin{array}{l}\text { ACB } \\
\text { complex }\end{array}$} & $\begin{array}{l}\text { A. calcoaceticus } \\
\text { (3) }\end{array}$ & $A(3)$ & $\begin{array}{l}\text { A. calcoaceticus/ } \\
\text { A. pittii (3) }\end{array}$ & $\begin{array}{l}\text { A. calcoaceticus/ } \\
\text { A. pittii (3) }\end{array}$ & $\begin{array}{l}\text { A. baumannii } \\
\text { complex (3) }\end{array}$ & $\begin{array}{l}\text { Acinetobacter } \\
\text { spp. (3) }\end{array}$ & $\begin{array}{l}\text { A. baumannii } \\
\text { (3) }\end{array}$ \\
\hline & $\begin{array}{l}\text { A. bаиатппіi } \\
\text { (92) }\end{array}$ & $\begin{array}{l}\mathrm{A}(76) \\
\mathrm{B}(16)\end{array}$ & $\begin{array}{l}\text { A. baumannii } \\
\text { (92) }\end{array}$ & $\begin{array}{l}\text { A. baumannii } \\
\text { (92) }\end{array}$ & $\begin{array}{l}\text { A. baumannii } \\
\text { complex (92) }\end{array}$ & $\begin{array}{l}\text { A. baumannii } \\
\qquad(92)\end{array}$ & $\begin{array}{l}\text { A. baumannii } \\
\text { (92) }\end{array}$ \\
\hline & $\begin{array}{l}\text { A. pittii } \\
\text { (9) }\end{array}$ & $\mathrm{A}(9)$ & $\begin{array}{l}\text { A. calcoaceticus/ } \\
\text { A. pittii (9) }\end{array}$ & $\begin{array}{l}\text { A. calcoaceticus/ } \\
\text { A. pittii (9) }\end{array}$ & $\begin{array}{l}\text { A. baumannii } \\
\text { complex (9) }\end{array}$ & $\begin{array}{l}\text { Acinetobacter } \\
\text { spp. (9) }\end{array}$ & $\begin{array}{l}\text { A. baumannii } \\
\text { (9) }\end{array}$ \\
\hline & $\begin{array}{c}\text { A. nosocomialis } \\
\text { (13) }\end{array}$ & $\mathrm{A}(13)$ & $\begin{array}{l}\text { A. nosocomialis } \\
\text { (13) }\end{array}$ & $\begin{array}{c}\text { A. nosocomialis/ } \\
\text { A. calcoaceticus (13) }\end{array}$ & $\begin{array}{l}\text { A. baumannii } \\
\text { complex (13) }\end{array}$ & $\begin{array}{l}\text { A. baumannii } \\
\text { (13) }\end{array}$ & $\begin{array}{l}\text { A. baumannii } \\
\text { (13) }\end{array}$ \\
\hline $\begin{array}{l}\text { Non-ACB } \\
\text { complex }\end{array}$ & $\begin{array}{l}\text { A. soli } \\
\text { (6) }\end{array}$ & $\mathrm{C}(6)$ & $\begin{array}{l}\text { A. soli } \\
\text { (6) }\end{array}$ & $\begin{array}{c}\text { A. solil } \\
\text { A. baumannii (6) }\end{array}$ & $\begin{array}{l}\text { No ID } \\
(6)\end{array}$ & $\begin{array}{l}\text { No ID } \\
(6)\end{array}$ & $\begin{array}{l}\text { A. baumannii } \\
\text { (6) }\end{array}$ \\
\hline
\end{tabular}

ACB: A. calcoaceticus-A. baumannii complex, ITS: internal transcribed spacer, MALDI-TOF MS: matrix-assisted laser desorption/ionization time-of-flight mass spectrometry.

fied: A. baumannii (genospecies 2), 92 isolates (74.8\%); $A$. nosocomialis (genospecies 13TU), 13 isolates (10.6\%); $A$. calcoaceticus or A. pittii (genospecies 1 or 3), 12 isolates $(9.7 \%, 12$ isolates were incorrectly identified as A. calcoaceticus or A. pittii); and A. soli, 6 isolates (4.9\%) isolates (Table 2).
The $r p o B$ gene sequencing correctly identified 117 isolates $(95.1 \%)$ belonging to ACB-complex. Only 6 isolates $(4.9 \%)$ belonging to non-ACB complex.

\section{Phylogenetic analysis using partial rpoB gene sequences}

The sequences of part of the $r p o B$ gene (approximately 


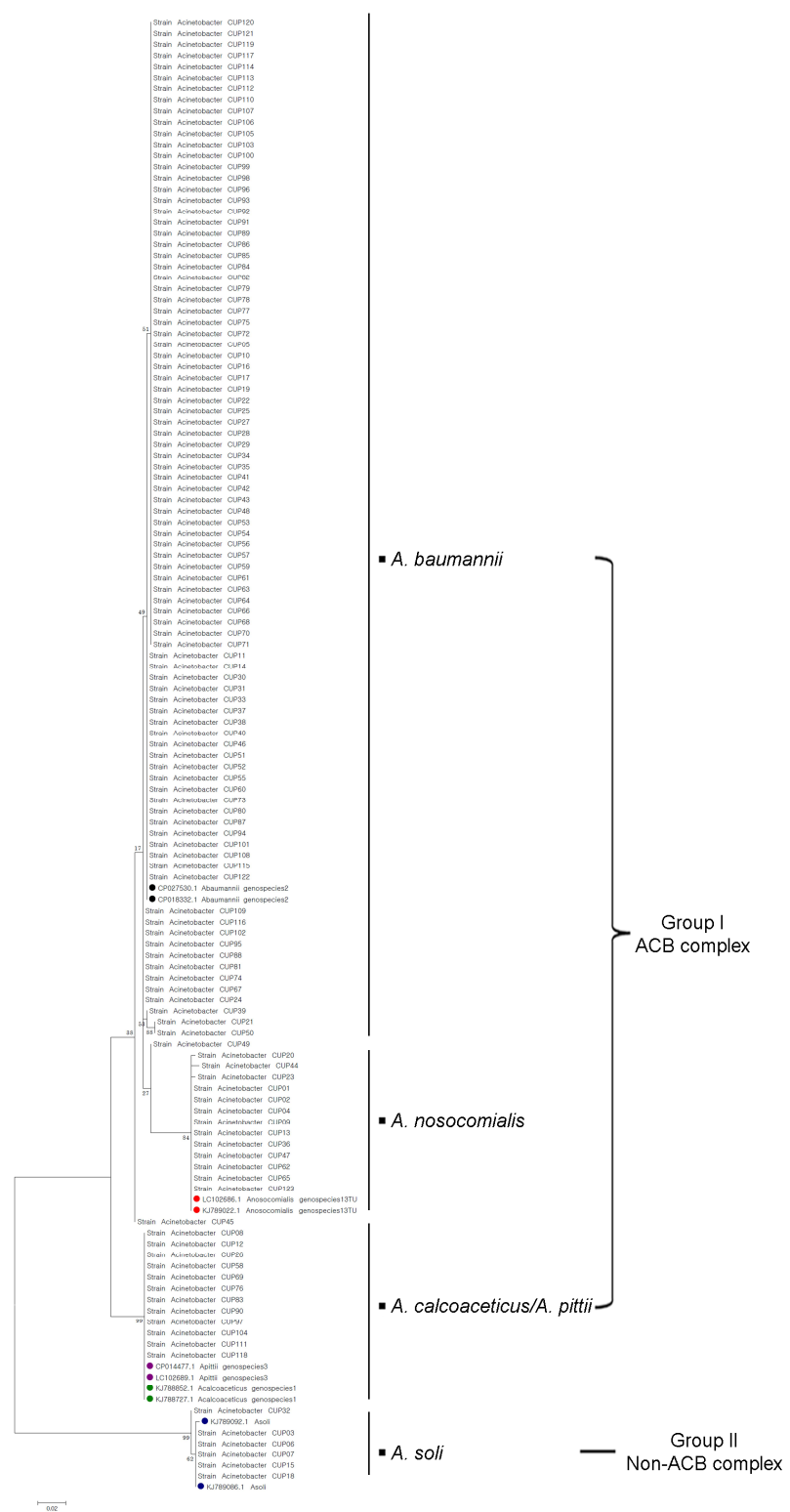

Fig. 3. A phylogenetic tree based on $r p o B$ gene sequences shows the relationship of the 123 Acinetobacter clinical isolates. Numbers on branches indicate percentages of the number of times that the node was supported in 1,000 replicates of bootstrap analysis. Scale bar, 0.02 substitutions per site (Supplementary data 2).

$380 \mathrm{bp)}$ from all Acinetobacter isolates were aligned and edited, and the following sequences were used as reference strains: A. calcoaceticus (GenBank accession number: KJ788852 and KJ788727), A. baumannii (GenBank accession number: CP027530 and CP018332), A. pittii (GenBank accession number: CP014477 and LC102689), A. nosocomialis
(GenBank accession number: LC102686 and KJ789022) and A. soli (GenBank accession number: KJ789086 and KJ789092). The Acinetobacter clinical isolates were separated into two major groups (group I and II) based on the phylogenetic tree constructed using ML. Group I comprised $A$. calcoaceticus, A. baumannii, A. pittii and A. nosocomialis, in which Acinetobacter genospecies 1 3 were observed to be closely grouped. This clustering was supported by high bootstrap value of $99 \%$. Group II comprised A. soli (a bootstrap values of 99\%) (Fig. 3).

\section{Genotypic identification of Acinetobacter spp. isolates using ITS region sequencing}

One-hundred and twenty three Acinetobacter clinical isolates were analyzed using ITS region genotyping. PCR amplification results for the ITS region are provided in Fig. 2 .

As a result of ITS region sequencing, the 5 Acinetobacter spp. were as follows: A. baumannii (genospecies 2), 92 isolates $(74.8 \%)$; A. nosocomialis or A. calcoaceticus (genospecies 13TU or 1), 13 isolates $(10.6 \%, 13$ isolates were incorrectly identified as A. nosocomialis or A. calcoaceticus); A. calcoaceticus, A. pittii or A. baumannii (genospecies 1, 3 or 2), 12 isolates $(9.7 \%, 12$ isolates were incorrectly identified as A. calcoaceticus, A. pittii or A. baumannii); and A. soli or A. baumannii, 6 isolates (4.9\%, isolates were incorrectly identified as A. soli or A. baumannii) isolates (Table 2). Thus, the findings using ITS region sequencing were relatively less accurate than those obtained using $r p o B$ gene sequencing.

\section{Molecular analysis of Acinetobacter spp. isolates by ARDRA}

For genospecies identification of isolates, ARDRA of the ITS region was applied as previously described by Vaneechoutte et al. (Vaneechoutte et al., 1995). ITS region of 16 23S rRNA gene was amplified for a total of 123 isolates belonging to the 5 species of the genus Acinetobacter and amplified product was restricted independently with a total of 5 different endonucleases (AluI, HhaI, HaeIII, MboI, and $M S P I)$. Each enzyme generated up to 5 fragments per isolates.

Fig. 4 shows an overview of different restriction patterns observed. Digestion of the ITS region by AluI resulted in 2 

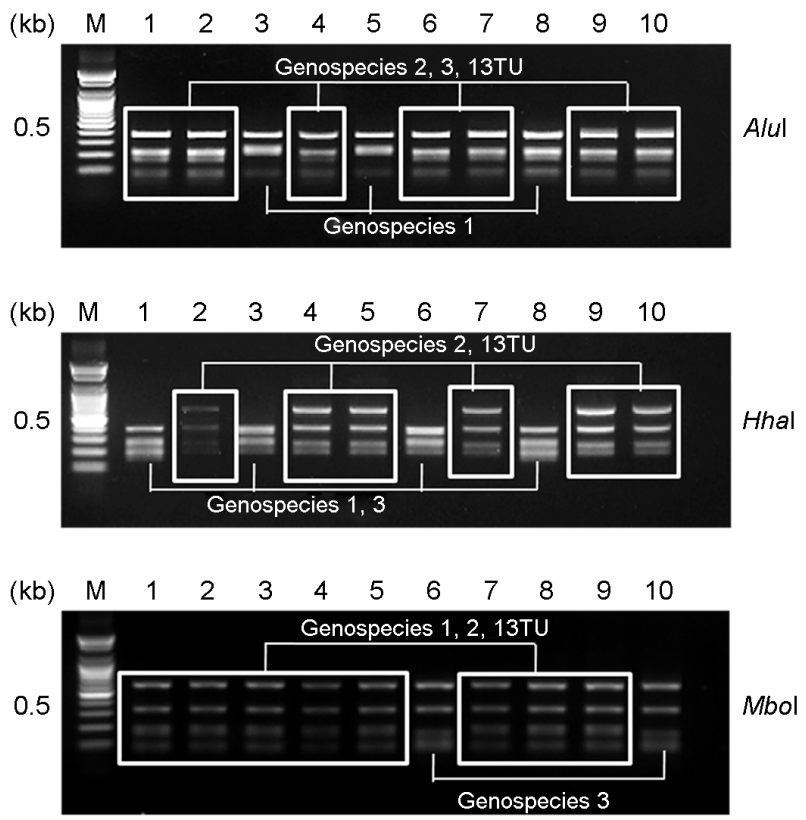

Fig. 4. ARDRA patterns of Acinetobacter clinical isolates obtained after restriction of amplified ITS region with three different enzymes (AluI, HhaI, and MboI). Lanes M; molecular size marker, 1 10; clinical isolates.

different patterns. Genospecies 2, 3, and 13TU (A. baumannii, A. pittii, and A. nosocomialis) isolates were digested into three different size fragments. Genospecies 1 (A. calcoaceticus) isolates were digested into two different size fragment. Digestion by HhaI resulted in 2 different patterns. Genospecies 1 and 3 isolates were digested into four different size fragments. Genospecies 2 and 13TU isolates were digested into three different size fragments. Digestion by $M b o \mathrm{I}$ resulted in 2 different patterns. Genospecies 1, 2, 13TU isolates were four different size fragments. Genospecies 3 isolates were digested into four different size fragments. Genospecies 3 isolates were digested into three different size fragments. Combination of the patterns obtained after separate restriction with $A l u \mathrm{I}, H h a \mathrm{I}$ and $\mathrm{MboI}$ enabled us to identify the 4 genospecies of Acinetobacter spp. isolates. Therefore, four species (1, 2, 3 and 13TU) of Acinetobacter isolates were determined by three endonucleases ( $A l u \mathrm{I}, \mathrm{Hha \textrm {I }}$ and $\mathrm{Mbo \textrm {I }}$ ). However, A. soli isolates were not differentiated from other species of Acinetobacter isolates, in this study.

After analysis for ARDRA of ITS region, the 5 Acinetobacter spp. were identified correctly: A. baumannii (geno- species 2), 92 isolates (74.8\%); A. nosocomialis (genospecies 13TU), 13 isolates (10.6\%); A. pittii (genospecies 3), 9 isolates (7.3\%); A. soli, 6 isolates (4.9\%) isolates; and A. calcoacetius (genospecies 1$), 3$ isolates $(2.4 \%)$.

\section{MALDI-TOF MS analysis using the VITEK ${ }^{\circledR}$ MS for species identification of Acinetobacter isolates}

MALDI-TOF MS is a useful method of identifying bacteria and has several benefits. The identification results obtained from the use of two distinct test system $\left(\mathrm{VITEK}^{\circledR}\right.$ MS: IVD 2.0 and RUO) that were applied to the 123 isolates are summarized in Table 2. One-hundred and seventeen isolates $(95.1 \%)$ identified as A. baumannii complex using the VITEK ${ }^{\circledR}$-MS IVD 2.0 system. Six isolates (4.9\%) were not identified. One-hundred and five isolates $(85.4 \%)$ were identified as $A$. baumannii using the VITEK $^{\circledR}$-MS RUO system. Twelve isolates (9.7\%) of Acinetobacter spp. identified at the genus level. Six isolates (4.9\%) were not identified. Each group showed very similar peak profiles, but there were some significant differences between both groups (Fig. 5).

\section{Distribution of Acinetobacter spp. isolates by various clinical samples}

A. baumannii accounted for $74.8 \%$ of the 123 Acinetobacter spp. isolates $(\mathrm{n}=92)$, and non-baumannii Acinetobacter spp. accounted for $25.2 \%(\mathrm{n}=31)$. The distribution of Acinetobacter spp. isolates by clinical samples is depicted in Table 3. A. baumannii was most frequently isolated in all 123 clinical samples (sputum, blood, urine, foley tip, pus discharge, bronchial fluid, wound and ear discharge). A. baumannii only was isolated in pus discharge, the tips of Foley catheters, and wound and bronchial fluid samples (100.0\%). All of the $A$. soli isolates $(\mathrm{n}=6,100.0 \%)$ were isolated in sputum samples.

\section{DISCUSSION}

The proportions of Acinetobacter spp. isolates has been reported in several previous studies. According to these studies, A. baumannii (genospecies 2) is known as the most common species of Acinetobacter cause of nosocomial infections. However, the growing number of new infections 
A

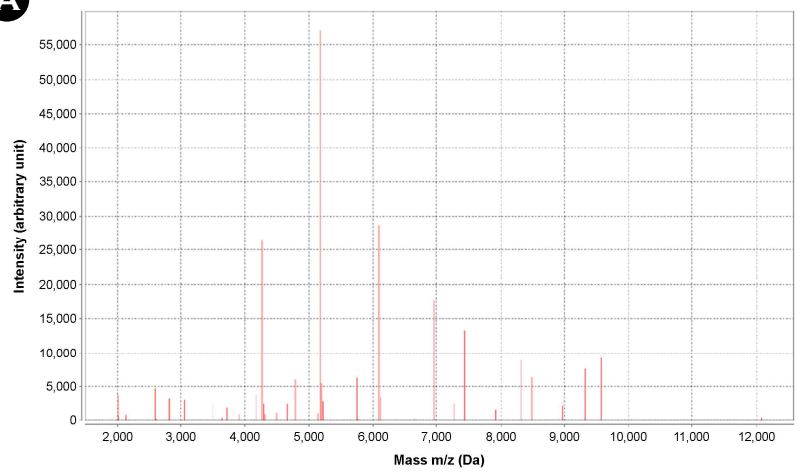

C

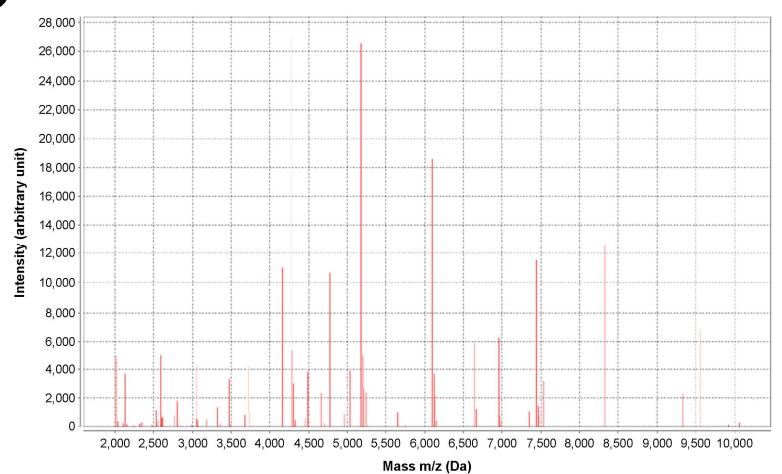

B

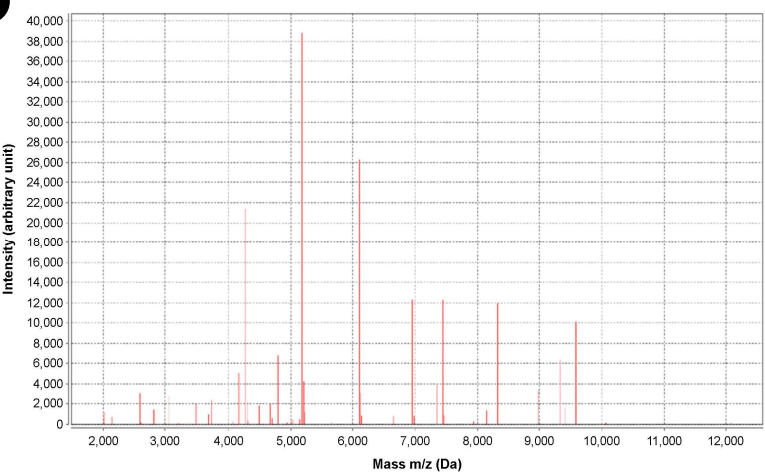

(D)

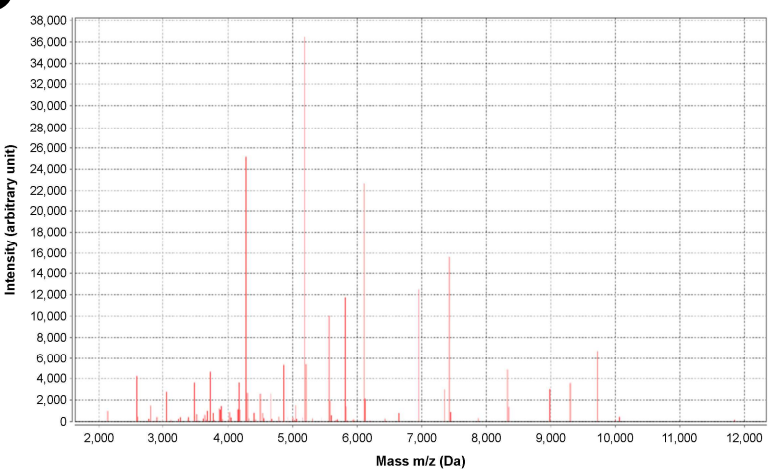

Fig. 5. Peak profiles of four representative Acinetobacter species isolates generated by MALDI-TOF MS based VITEK MS. The X-axis shows the $\mathrm{m} / \mathrm{z}$ values and the $y$-axis indicates of the peaks expressed in arbitrary intensity units. (A) Peak profile of A. baumannii isolate. (B) Peak profile of A. nosocomialis isolate. (C) Peak profile of A. pittii isolate. (D) Peak profile of A. soli isolate.

Table 3. The distribution of Acinetobacter species isolates by clinical sample type

\begin{tabular}{lcccccc}
\hline & \multicolumn{5}{c}{ Isolates } & \multicolumn{5}{c}{ Acinetobacter species: $\mathrm{n}(\%)$} & \multirow{2}{*}{ Total (\%) } \\
\cline { 2 - 6 } Sample type & A. baumannii & A. calcoaceticus & A. nosocomialis & A. pittii & A. soli & \\
\hline Sputum & $45(66.2)$ & $2(2.9)$ & $10(14.7)$ & $5(7.4)$ & $6(8.8)$ & $68(55.3)$ \\
Urine & $9(64.3)$ & $1(7.1)$ & $1(7.1)$ & $3(21.4)$ & - & $14(11.4)$ \\
Blood & $15(88.2)$ & - & $1(5.9)$ & $1(5.9)$ & - & $17(13.8)$ \\
Bronchial fluid & $7(100.0)$ & - & - & - & - & $7(5.7)$ \\
Foley tip & $5(100.0)$ & - & - & - & - & $5(4.1)$ \\
Wound discharge & $6(100.0)$ & - & - & - & - & $6(4.9)$ \\
Pus discharge & $3(100.0)$ & - & - & - & - & $3(2.4)$ \\
Ear discharge & $2(66.7)$ & - & $13(10.6)$ & $9(7.3)$ & $6(4.9)$ & $123(100.0)$ \\
\hline Total $(\%)$ & $92(74.8)$ & $3(2.4)$ & &
\end{tabular}

from non-baumannii Acinetobacter species is increasingly being recognized, and non-baumannii Acinetobacter species have been identified as important contributors to nosocomial infection (Lee et al., 2011; Visca et al., 2011; Antunes et al.,
2014). The distribution of Acinetobacter spp. isolates, collected from two general hospitals, in Busan, Korea, was evaluated in the current study. A. baumannii isolates (74.8\%, 92/ 123 ) were the most common species, $A$. nosocomialis isolates 
$(10.6 \%, 13 / 123)$ and A. pittii isolates $(7.5 \%, 9 / 123)$ were the second and third common strains of ACB-complex, respectively (Table 2). A different Acinetobacter species distribution to that reported in other studies was determined in the current research. According to Lee et al., A. baumannii (74.9\%), A. nosocomialis $(12.3 \%)$ and A. bereziniae (3.4\%, Genospecies 10; non-ACB complex) were the common species of Acinetobacter from 495 clinical isolates (collected from 2005 to 2012) in Korea (Lee et al., 2014). By contrast, $A$. bereziniae was not isolated, and A. soli $(5.0 \%, 6 / 123)$ was the most common non-ACB complex species, in the present study. (Endo et al., 2014) demonstrated that $A$. soli accounted for a high proportion of Acinetobacter isolates (27.1\%) that were the cause of bacteremia in a Japanese tertiary hospital (Endo et al., 2014). According to Khosravi et al., A. baumannii (66.0\%), A. calcoaceticus (4.5\%) and Acinetobacter genospecies 16 (4.0\%; non-ACB complex) were the most cited species of Acinetobacter identified in 197 clinical isolates (collected from 2011 to 2013) in Iran (Khosravi et al., 2015). These results show that the distribution of Acinetobacter spp. varies depending on geographical, institutional and epidemiolgical differences.

The genus Acinetobacter was originally suggested by Brisou and Prevot (1954). Since then, more than 30 Acinetobacter species have been described. The identification of Acinetobacter at the species level is difficult. The ACBcomplex species, in particular, are known to be a common cause of nosocomial infections. A. baumannii, A. calcoaceticus, $A$. pittii and $A$. nosocomialis are phenotypically very similar and genetically closely related (Vaneechoutte et al., 1995; Lee et al., 2011; Visca et al., 2011; Tien et al., 2012; Almasaudi, 2018). The accurate identification of bacterial pathogens is essential within a clinical laboratory. Various phenotypic and genotypic methods have been developed and validated to ensure the correct identification of different Acinetobacter spp. the $r p o B$ gene sequencing. ARDRA of the ITS region was demonstrated to have greater accuracy than other methods (i.e., ITS region sequencing, MALDITOF MS and VITEK ${ }^{\circledR} 2$ system) in species identification in the current research. However, the A. pittii and A. calcoaceticus isolates $(7.5 \%, 12 / 123)$ were not correctly differentiated from one another using $r p o B$ gene sequencing and phylo- genetic analysis. MALDI-TOF MS is presently the predominant method used to identify microorganisms in an increasing number of clinical laboratories. In the current study, the results obtained using the MALDI-TOF MS based VITEK $^{\circledR}$ MS system were superior to those obtained using a commercial biochemical approach (i.e., VITEK ${ }^{\circledR} 2$ ). However, 31 isolates $(25.2 \%)$ could not be identified at the species level. The rate for correct identification at the species level, misidentification, and the lack of identification was $74.8 \%$ (92/123), 20.3\% (25/123) and 4.9\% (6/123), respectively. Only A. baumannii isolates were correctly identified at the species level using VITEK ${ }^{\circledR}$ MS RUO mode. In the present study, isolates of $A$. soli, which are not included in VITEK ${ }^{\circledR}$ MS database, were not identified at all. The system database should be further expanded and optimized with respect to the species that were misidentified. Similarly, rare or recently named species should be added to the database in order to ensure more accurate identification when using MALDITOF-based VITEK ${ }^{\circledR}$ MS. Jeong et al. (2016) demonstrated that MALDI-TOF MS was a useful method of correctly identifying Acinetobacter isolates at the species level following updates to the database (Jeong et al., 2016).

Traditionally, colony formation of microorganisms and its morphological analysis (size, shape, surface and color) with a naked eye have been applied for detection and identification of microbial species (Maeda et al., 2017). In the current study, colonies of 123 Acinetobacter spp. isolates were observed on MacConkey agar, and colony based bacterial strain typing was performed. Three types of colonies were identified; (1) small size ( $<3 \mathrm{~mm})$, smooth, round shape and raised colonies (Group A), (2) medium size (3 5 mm), smooth, round shape and mucoid colonies (Group B), and (3) medium-large size (5 10 mm), rough, irregular shape and flat colonies (Group C). Group C was identified as A. soli only $(\mathrm{n}=6,100.0 \%)$. Like this result, colony morphological type was related with Acinetobacter spp., and considered to be one of useful species screening method in the clinic.

In conclusion, our study demonstrated that the $r p o B$ gene sequencing and ARDRA of ITS region of 16 23S rRNA seem to be very useful genotypic methods for the differentiation of Acinetobacter spp. at the species level. As a result, 123 Acinetobacter spp. isolates were identified correctly: $A$. 
baumannii (genospecies 2), 92 isolates (74.8\%); A. nosocomialis (genospecies 13TU), 13 isolates (10.6\%); A. pittii (genospecies 3), 9 isolates (7.3\%); A. soli, 6 isolates (4.9\%) isolates; and A. calcoacetius (genospecies 1), 3 isolates (2.4\%).

\section{ACKNOWLEDGEMENT}

This paper was supported by a research fund offered from the Catholic University of Pusan, Republic of Korea in 2015.

\section{CONFLICT OF INTEREST}

No potential conflict of interest relevant to this article was reported.

\section{REFERENCES}

Almasaudi SB. Acinetobacter spp. as nosocomial pathogens: Epidemiology and resistance features. Saudi J Biol Sci. 2018. 25: 586-596.

Antunes LC, Visca P, Towner KJ. Acinetobacter baumannii: evolution of a global pathogen. Pathog Dis. 2014. 71: 292-301.

Cisneros JM, Rodriguez-Bano J. Nosocomial bacteremia due to Acinetobacter baumannii: epidemiology, clinical features and treatment. Clin Microbiol Infect. 2002. 8: 687-693.

Croxatto A, Prod'hom G, Greub G. Applications of MALDI-TOF mass spectrometry in clinical diagnostic microbiology. FEMS Microbiol Rev. 2012. 36: 380-407.

Dingle TC, Butler-Wu SM. Maldi-tof mass spectrometry for microorganism identification. Clin Lab Med. 2013. 33: 589-609.

Endo S, Yano H, Kanamori H, Inomata S, Aoyagi T, Hatta M, Gu Y, Tokuda K, Kitagawa M, Kaku M. High frequency of Acinetobacter soli among Acinetobacter isolates causing bacteremia at a tertiary hospital in Japan. J Clini Microbiol. 2014. 52: 911-915.

Jeong S, Hong JS, Kim JO, Kim KH, Lee W, Bae IK, Lee K, Jeong SH. Identification of Acinetobacter Species Using MatrixAssisted Laser Desorption Ionization-Time of Flight Mass Spectrometry. Ann Lab Med. 2016. 36: 325-334.

Khosravi AD, Sadeghi P, Shahraki AH, Heidarieh P, Sheikhi N. Molecular methods for identification of Acinetobacter species by partial sequencing of the $r p o B$ and 16SrRNA genes. J Clin Diagn Res. 2015. 9: DC09-13.

Koeleman JG, Stoof J, Biesmans DJ, Savelkoul PH, Vandenbroucke-
Grauls CM. Comparison of amplified ribosomal DNA restriction analysis, random amplified polymorphic DNA analysis, and amplified fragment length polymorphism fingerprinting for identification of Acinetobacter genomic species and typing of Acinetobacter baumannii. J Clin Microbiol. 1998. 36: 2522 -2529 .

La Scola B, Gundi VA, Khamis A, Raoult D. Sequencing of the $r p o B$ gene and flanking spacers for molecular identification of Acinetobacter species. J Clin Microbiol. 2006. 44: 827-832.

Lee MJ, Jang SJ, Li XM, Park G, Kook JK, Kim MJ, Chang YH, Shin JH, Kim SH, Kim DM, Kang SH, Moon DS. Comparison of $r p o B$ gene sequencing, $16 \mathrm{~S}$ rRNA gene sequencing, $g y r B$ multiplex PCR, and the VITEK2 system for identification of Acinetobacter clinical isolates. Diagn Microbiol Infect Dis. 2014. 78: 29-34.

Lee K, Yong D, Jeong SH, Chong Y. Multidrug-resistant Acinetobacter spp.: increasingly problematic nosocomial pathogens. Yonsei Med J. 2011. 52: 879-891.

Maeda Y, Dobashi H, Sugiyama Y, Saeki T, Lim TK, Harada M, Matsunaga T, Yoshino T, Tanaka T. Colony fingerprint for discrimination of microbial species on lensless imaging of microcolonies. PLos One. 2017. 12: e0174723.

Tien N, You BJ, Chang HL, Lin HS, Lee CY, Chung TC, Lu JJ, Chang CC. Comparison of genospecies and antimicrobial resistance profiles of isolates in the Acinetobacter calcoaceticusAcinetobacter baumannii complex from various clinical specimens. Antimicrob Agents Chemother. 2012. 56: 6267-6271.

Vaneechoutte M, Dijkshoorn L, Tjernberg I, Elaichouni A, de Vos P, Claeys G, Verschraegen G. Identification of Acinetobacter genomic species by amplified ribosomal DNA restriction analysis. J Clin Microbiol. 1995. 33: 11-15.

Visca P, Seifert H, Towner KJ. Acinetobacter infection-an emerging threat to human health. IUBMB Life. 2011. 63: 1048-1054.

Wang J, Ruan Z, Feng Y, Fu Y, Jiang Y, Wang H, Yu Y. Species distribution of clinical Acinetobacter isolates revealed by different identification techniques. PLoS One. 2014. 9: e104882.

https://doi.org/10.15616/BSL.2019.25.1.40

Cite this article as: Park GN, Kang HS, Kim HR, Jung BK, Kim DH, Chang KS. A Comparison of Genospecies of Clinical Isolates in the Acinetobacter spp. Complex Obtained from Hospitalized Patients in Busan, Korea. Biomedical Science Letters. 2019. 25: 40-53. 